Saudi Journal of Oral and Dental Research

Abbreviated Key Title: Saudi J Oral Dent Res

ISSN 2518-1300 (Print) |ISSN 2518-1297 (Online)

Scholars Middle East Publishers, Dubai, United Arab Emirates

Journal homepage: https://saudijournals.com/sjodr

\title{
A Comparative Study of Skeletal and Dental Changes in Fixed Functional and Removable Functional Appliance Therapy
}

Dr. Anshu Singh MDS $^{1 *}$, Dr. Hitesh Ramdas Sawant ${ }^{2}$, Dr. Prasad Anand Khudare ${ }^{3}$, Dr. Dhananjay Rathod ${ }^{4}$, Dr. Nitin Gadhiya $^{5}$, Dr. Sameer Narkhede ${ }^{6}$

${ }^{1}$ Senior Lecturer Department of Orthodontics, Awadh Dental College and Hospital, Jamshedpur, Jharkhand India

${ }^{2}$ PG Student, Dept of Orthodontics \& Dentofacial Orthopaedics, Bharati Vidyapeeth Deemed to be University Dental College and Hospital, Navi Mumbai India

${ }^{3}$ Senior Lecturer, Dept of Orthodontics, Saraswati Dhanvantari Dental College and Hospital, Parbhani, Maharashtra India

${ }^{4}$ Assistant professor, Department of Orthodontics, Hazaribagh College of Dental sciences, hazaribagh, Jharkhand India

${ }^{5}$ Professor, Department of Orthodontics \& Dentofacial Orthopaedics, Dr D Y Patil Dental College, Navi Mumbai India

${ }^{6}$ Professor, Department of Orthodontics \& Dentofacial Orthopaedics, Dr D Y Patil Dental College, Navi Mumbai India

DOI: $10.36348 /$ sjodr.2020.v05i10.004

| Received: 08.10.2020 | Accepted: 16.10.2020 | Published: 21.10 .2020

*Corresponding author: Dr. Anshu Singh MDS

Abstract

Background: Functional appliance therapy has gained popularity and has been used with substantial amount of success in the management of skeletal class II malocclusion. Generally, functional appliances are utilized for the correction of retruded mandible in growing individuals. This study was used to compare and plot the skeletal and dental changes using fixed and removable functional appliance therapy in the treatment of class II malocclusion. Materials and methods: The study population consist of 50 growing individuals who have undergone treatment for skeletal class II malocclusion. The group are divided in to herbst group $(n=25)$ and twin block group $(n=25)$. The lateral cephalograms obtained from these patients and changes analyzed using students paired t -test. Results: The skeletal and dental changes showed statistically significant improvement in antero-posterior maxillomandibular measurement in both groups and but herbst unlike twinblock produce greater dental effects. Although treatment duration was faster in fixed appliance group, both studies showed improved facial profile. Conclusion: The treatment effects of both the functional appliances used in this study for skeletal class II cases are satisfactory and can effectively use for correction of retrognathic mandible in adolescents.

Keywords: Fixed Applaince, Removable Applaince, Skeletal, Dental, Orthodontic Therapy.

Copyright (C) 2020 The Author(s): This is an open-access article distributed under the terms of the Creative Commons Attribution 4.0 International License (CC BY-NC 4.0) which permits unrestricted use, distribution, and reproduction in any medium for non-commercial use provided the original author and source are credited.

\section{INTRODUCTION}

The key to the successful management of skeletal class II malocclusion is by giving early orthodontic growth modification treatment. The major reason for class II malocclusion is retrognathic mandible and as per biological evidence all the orthopaedic interventions are aimed to bring the mandible forward with functional appliance therapy [1].Since years several functional appliances have developed removable, fixed and hybrid appliance [2]. Functional appliances help in positioning the lower jaw forward to an edge-to-edge relationship, thereby disoccluding the posterior teeth, which are then free to erupt. There is numerous literatures which evaluates the effect of functional appliances in different phases of treatment. As discussed in a systematic review, the most advantageous of functional appliances are Herbst and Twin- block appliances [5]. To overcome the shortcomings of removable functional appliances fixed functional appliance are incorporated. The present study was aimed to compare and assess the dentoskeletal effects of fixed and removable functional appliance in individuals with skeletal class II malocclusion.

\section{MATERIALS AND METHODS}

The study population consist of 50 patients with skeletal class II malocclusion. The records of the treatment undergone were obtained from different dental colleges across country. The subjects were divided in to Herbst group (fixed functional appliance) and consisted of 25 subjects. The next group of 25 were subjects treated with twin block group (removable functional appliance). Out of 50 subjects 35 were male and 15 were female. The mean age of patients in the Herbst group is (12+/- 1.19 years) and mean age of patients in twin block group was $(12.47+/-1.24$ years $)$ .The inclusion criteria included patient who received 
full orthodontic treatment and with quality pre and post treatment records available. The exclusion criteria involve patients with craniofacial syndromes and facial asymmetry. Lateral cephalometric radiographic films and data were collected before the beginning of treatment and after the treatment. Cephalogram films were traced with the Pancherz analysis and superimposed by the examiner unaware of the group to which the patient had been allocated the intergroup group evaluation and analysis done using paired t-tests.

\section{RESULTS}

The total 50 subjects were enrolled in the study. The mean age of patients in the Herbst group is $12+/-1.19$ years) and mean age of patients in twin block group was $12.47+/-1.24$ years. The data obtained after superimposition were statistically analysed. Statistical comparison and descriptive comparison of herbst group and twin block group are given in table 1 and table 2. Significant difference was found in all the cephalometric measurements in both groups before and after treatment. With regard to dental changes, the results demonstrated that overjet and overbite is reduced in both treatment groups. The anterior-posterior skeletal discrepancy improved and the mandibular length increased significantly in both groups although duration of treatment was shorter for herbst group. The change in the vertical dimensions was reported and showed significant increase for Herbst and twin block in the lower anterior and posterior face height and ramus height.

Table-1: Comparison of baseline cephalometric measurements after treatment

\begin{tabular}{|c|c|c|c|c|c|}
\hline \multirow{2}{*}{\multicolumn{2}{|c|}{ Skeletal measurements }} & \multicolumn{2}{|c|}{ HERBST } & \multicolumn{2}{|c|}{ TWIN BLOCK } \\
\hline & & MEAN & S.D & MEAN & SD \\
\hline \multicolumn{2}{|l|}{ SNA } & 80.88 & 1.13 & 80.33 & 0.94 \\
\hline \multicolumn{2}{|l|}{ SNB } & 72.18 & 2.07 & 74.74 & 1.77 \\
\hline \multicolumn{2}{|l|}{ ANB } & 7.6 & 1.54 & 6.08 & 1.18 \\
\hline \multicolumn{2}{|l|}{ Overjet (is/OLp minus ii/OLp) } & 8.92 & 2.82 & 8.24 & 2.31 \\
\hline \multicolumn{2}{|l|}{ Maxillary baseA/OLp } & 80.89 & 4.67 & 81.55 & 5.23 \\
\hline \multicolumn{2}{|c|}{ Mandibular basePg/OLp } & 81.92 & 3.87 & 83.43 & 6.08 \\
\hline \multicolumn{2}{|c|}{ (A/OLp-Pg/OLp) (skeletal discrepancy) } & -0.88 & 3.17 & -1.77 & 4.14 \\
\hline \multicolumn{2}{|c|}{$\mathrm{Co} / \mathrm{OLp}$} & 11.22 & 2.56 & 12.06 & 3.46 \\
\hline \multicolumn{2}{|c|}{ Comp mandi length Pg/OLp + Co/OLp } & 92.90 & 3.98 & 95.32 & 4.86 \\
\hline \multicolumn{2}{|c|}{ Ramus height (Co-Go)5 } & 52.76 & 4.85 & 54.96 & 3.42 \\
\hline \multicolumn{2}{|l|}{ Effective mandibular lengthGo-Gn } & 112.67 & 5.79 & 114.34 & 5.52 \\
\hline \multicolumn{2}{|l|}{ Lower anterior face height } & 67.34 & 5.46 & 66.34 & 5.63 \\
\hline \multicolumn{2}{|l|}{ Lower posterior face heightS-Go } & 77.85 & 4.93 & 78.12 & 4.91 \\
\hline \multirow[t]{2}{*}{ Dentoalveolar measurements } & \multicolumn{2}{|c|}{ Herbst } & \multicolumn{3}{|c|}{ Twin block } \\
\hline & MEAN & SD & \multicolumn{2}{|c|}{ MEAN } & S.D \\
\hline Ils/NL & -1.00 & 7.11 & \multicolumn{2}{|c|}{-4.40} & 12.3 \\
\hline Ili/ML & 5.65 & 4.16 & \multicolumn{2}{|c|}{1.40} & 8.40 \\
\hline Ils-NL & 1.35 & 2.23 & \multicolumn{2}{|l|}{2.45} & 2.75 \\
\hline Ils-ML & -0.80 & 1.31 & \multicolumn{2}{|l|}{0.80} & 3.06 \\
\hline Ms-NL & -0.90 & 1.98 & \multicolumn{2}{|l|}{1.30} & 3.29 \\
\hline Mi-Ml & 2.15 & 2.51 & \multicolumn{2}{|l|}{1.05} & 2.60 \\
\hline
\end{tabular}

Table-2: Change in Pancherz analysis variables

\begin{tabular}{|l|l|l|l|l|}
\hline & \multicolumn{2}{|l|}{ TWIN BLOCK } & \multicolumn{2}{l|}{ HERBST } \\
\hline SKELTAL & MEAN & 95\%Cl & MEAN & 95\% Cl \\
\hline Maxillary base (A point to OLp) & 1.85 & 1.2 to 2.4 & 1.22 & 0.70 to 1.74 \\
\hline Mandibular base (Pg/OLp) & 4.42 & 3.63 to5.2 & 3.66 & 2.89 to4.43 \\
\hline Condylar head (Co/OLp) & -0.96 & -0.51 to-1.39 & -0.30 & 0.67 to0.08 \\
\hline Mandibular length (Pg/OLpCo/OLp) & 3.46 & 2.45 to4.47 & 3.36 & 2.51 to 4.21 \\
\hline DENTAL & & & & \\
\hline Maxillary incisor (Is/OLpSs/OLp) & -3.11 & -2.31 to-3.91 & -2.43 & -3.00 to- 1.85 \\
\hline Mandibular incisor (Ii/OLpPg/OLp) & 0.56 & -0.29 to1.13 & 0.94 & 0.37 to 1.51 \\
\hline Maxillary molar (Ms/OlpSs/OLp) & 0.40 & -0.21 to1.020 & 0.48 & 0.19 to 1.14 \\
\hline Mandibular molar (Mi/OLpPg/OLp) & 1.45 & .66 to 2.55 & 1.07 & 0.61 to 1.53 \\
\hline
\end{tabular}

\section{DISCUSSION}

One of the important therapeutic implications of functional appliance is the management of skeletal calss II malocclusion in growing individuals. According to Bacetti et al., functional appliance has optimum therapeutic effect in the peak of pre-pubertal period. The present study evaluated and compared dental and skeletal changes in patients with skeletal classII malocclusion in two treatment groups. Herbst appliance which is one of the the historically prominent rigid 
fixed appliance was used in one group. It was invented by Herbst in 1900's (40) and reintroduced by Pancherz at the end of 1970's. The other group were delivered removable twin block appliance after finishing the active treatment period and the patients were instructed to wear the appliance to achieve stable mandibular postion. We found that considerable correction of class II malocclusion was achieved in both treatment groups. Interpretion of the values from the lateral cephalogram and dent skeletal effects evaluated by pancherz analyzis which is gold standarnd for functional appliance studies [8], Herbst and Twin Block appliances both result in significant and similar improvement of the facial profile. It was found that Herbst and Twin-block appliances showed increased anteroposterior postioning of mandibular jaw, but the prominent changes are mostly dent alveolar. As observed from our study upper incisor protrusion (overjet) is reduced to normal limits and it was statistically significant. In case of herbst appliance it favours results not by growth of mandible but by distalizing the maxillary molars and restricting maxillary growth called as 'headgear effect". Significant incisior correction and dental change were seen in herbst group in our study which is consistent with findings of other literatures [9]. For patients in growth period, when the skeletal and dental contributions to overjet and molar correction percentages were evaluated, two-thirds of overall treatment effects of twiblock therapy could be attributed to skeletal changes. In twin block group, correction can cause equal and opposite forces in the maxilla as a response to mandibular downward and forward movement. In our study after 6 month period a decrease in SNA angle was seen, but neither of these appliances restricts the growth of maxilla. However, controversial results have reported in many literatures $[10,11]$. With regard to mandibular changes, we saw that twin block therapy led to greater increase in the forward positioning of the mandible compared with Herbst therapy. In our study the difference in effective increase in mandibular measurement between two groups is $1.57 \pm 3.03 \mathrm{~mm}$.In a study Schaefer et al. Twin block group showed additional increase in mandibular growth [12] which were similar to our results. It was shown that twin block group also resulted in greater improvement compared to Herbst group, when skeletal discrepancy was evaluated. This overall increase in mandibular length can be attributed to ramus height increase. While herbst group also showed improvement in mandibular length, increase in SNB angle and Go-Gn length, but statistically significant greater increases were found for mandibular base, composite mandibular length, and effective mandibular length compared to twin block group

\section{CONCLUSION}

The functional devices regardless of their type successfully reduced the overjet to within normal limits and the end of treatment both the appliance provided significant improvement in skeletal mandibular parameters .The findings from our study suggest that Twin-block appliance showed more skeletal changes and the Herbst appliance showed more dental changes.

\section{REFERENCES}

1. McNamara, J. A., Brudon, W. L., \& Kokich, V. G. (2001). Orthodontics and dentofacial orthopedics (pp. 67-80). Ann Arbor, Mich: Needham Press.

2. Marsico, E., Gatto, E., Burrascano, M., Matarese, G., \& Cordasco, G. (2011). Effectiveness of orthodontic treatment with functional appliances on mandibular growth in the short term. American Journal of Orthodontics and Dentofacial Orthopedics, 139(1), 24-36.

3. Nelson, C., Harkness, M., \& Herbison, P. (1993). Mandibular changes during functional appliance treatment. American Journal of Orthodontics and Dentofacial Orthopedics, 104(2), 153-161.

4. Illing, H. M., Morris, D. O., \& Lee, R. T. (1998). A prospective evaluation of Bass, Bionator and Twin Block appliances. Part I-The hard tissues. The European Journal of Orthodontics, 20(5), 501-516.

5. Cozza, P., Baccetti, T., Franchi, L., De Toffol, L., \& McNamara Jr, J. A. (2006). Mandibular changes produced by functional appliances in Class II malocclusion: a systematic review. American Journal of Orthodontics and Dentofacial Orthopedics, 129(5), 599-e1.

6. Baccetti, T., Franchi, L., Toth, L. R., \& McNamara Jr, J. A. (2000). Treatment timing for Twin-block therapy. American Journal of Orthodontics and Dentofacial Orthopedics, 118(2), 159-170.

7. Herbst, E. (1910). Atlas und Grundriss der zahnärztlichen Orthopädie. Lehmann.

8. Pancherz, H., \& Anehus-Pancherz, M. (1993). The headgear effect of the Herbst appliance: a cephalometric long-term study. American journal of orthodontics and dentofacial orthopedics, 103(6), 510-520.

9. Pancherz, H. (1982). The mechanism of Class II correction in Herbst appliance treatment: a cephalometric investigation. American Journal of Orthodontics, 82(2), 104-113.

10. Mills, C. M., \& McCulloch, K. J. (1998). Treatment effects of the twin block appliance: a cephalometric study. American Journal of Orthodontics and Dentofacial Orthopedics, 114(1), 15-24.

11. Tümer, N., \& Gültan, A. S. (1999). Comparison of the effects of monoblock and twin-block appliances on the skeletal and dentoalveolar structures. American Journal of Orthodontics and Dentofacial Orthopedics, 116(4), 460-468.

12. Schaefer, A. T., McNamara Jr, J. A., Franchi, L., \& Baccetti, T. (2004). A cephalometric comparison of treatment with the Twin-block and stainless steel crown Herbst appliances followed by fixed appliance therapy. American Journal of Orthodontics and Dentofacial Orthopedics, 126(1), 7-15. 